\title{
ESSENTIALS OF STOCHASTIC FINANCE
}

\author{
by Albert N. Shiryaev
}

\author{
A BOOK REVIEW \\ JORDAN STOYANOV \\ School of Mathematics \& Statistics \\ University of Newcastle Newcastle upon Tyne \\ NE1 7RU, United Kingdom \\ e-mail: jordan.stoyanov@ncl.ac.uk
}

(Received July, 1999; Revised January, 2000)

There was and still is a big "public noise" about applications of stochastics to financial business. At the core lies a deep interconnection between two seemingly quite different areas - Stochastic Calculus and Financial Stock Markets. Stochastic Calculus (SC) is a well-developed and well-established branch of contemporary mathematics requiring advanced ideas and techniques. Who could have predicted, say 30-40 years ago, that SC would become the "right" approach to analyzing complicated phenomena occurring in the world stock markets?

Not only has SC become a powerful theory but it has also become a powerful tool used in practice at the highest levels of decision-making in the financial world. Many universities throughout the world now have joint graduate programs in mathematics and finance. The field has attracted first-rate probabilists and statisticians, as well as practitioners in finance, and many of these have made great contributions to both the fundamental theory and the actual practice of finance.

The author of "Essentials of Stochastic Finance" is so well-known that he needs no introduction to the readers. Prof. Shiryaev is a leading expert in the area of SC and its applications (filtering theory, statistical inference, control theory, etc.). In addition to his great contributions, he initiated interest among Russian mathematicians in these important applications of SC. In light of recent history, it is perhaps not surprising that until 1989, all research in the area of stochastic finance was conducted in the West.

The present book is designed for readers who want to gain a theoretical and, to some extent, practical understanding of stochastic finance. It provides one of the most complete and systematic presentations of ideas and techniques in this area. Prof. Shiryaev is also well known as an excellent teacher, and his book reflects his rich international experience in teaching this subject matter at universities in Russia, Switzerland, Germany and Denmark.

The author's choice of material is outstanding and well worth the time and effort it will require to get through it. The book contains a number of very recent results 
that are only partly available in journals or other relatively obscure publications.

The book is divided into two parts, "Facts and Models" and "Theory", each consisting of four chapters. The eight chapters are:

I. Main Concepts, Structures and Instruments. Aims and Problems of Financial Theory and Financial Engineering.

II. Stochastic Models. Discrete Time.

III. Stochastic Models. Continuous Time.

IV. Statistical Analysis of Financial Data.

V. Theory of Arbitrage in Stochastic Financial Models. Discrete Time.

VI. Theory of Pricing in Stochastic Financial Models. Discrete Time.

VII. Theory of Arbitrage in Stochastic Financial Models. Continuous Time.

VIII. Theory of Pricing in Stochastic Financial Models. Continuous Time.

The book is very carefully written and contains detailed descriptions of the basic financial structures, instruments, markets, their stochastic models, and finally, the mathematical ideas and techniques needed to solve basic problems involving these models. As an example, for the stock-pricing problem, all ideas are appropriately introduced and well illustrated by examples described in terms of basic finance theory: share prices, exchange rates, interest rates, volatility, complete and incomplete markets, arbitrage-free markets, several kinds of options and other financial derivatives. The European and American "call" and "put" options and trading strategies are extensively examined in both discrete and continuous time models, and considerable attention is paid to the famous Black-Scholes model and to the binomial model. The recently introduced "Russian options" as well as a few others are also discussed. Solutions to option-pricing problems for each of these popular models are presented. These solutions involve a specially developed martingale theory, where everything is expressed in "financial" terms.

Although there is no shortage of good books on this topic, Prof. Shiryaev's book deserves special praise. For anyone interested or working in the field and who have a good mathematical background, this book will be a valuable resource and a rich and stimulating source of intellectual pleasure. Prof. Shiryaev, a great master, has produced a great book, which can be classified as a substantial piece of science and art. Moreover, in reading this book, the reader, without knowing it, will be on his/her way to the world stock markets.

Essentials of Stochastic Finance, by Albert N. Shiryaev

Publisher: World Scientific Publishing Co. Pte. Ltd.

Publication Year: 1999

ISBN 981-02-3605-0

Price: $\$ 113.00$ 


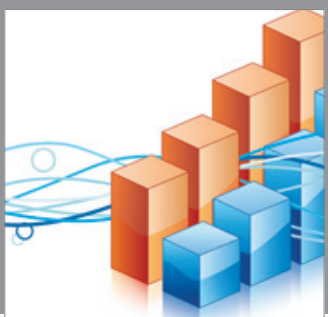

Advances in

Operations Research

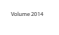

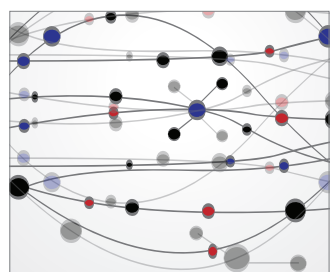

\section{The Scientific} World Journal
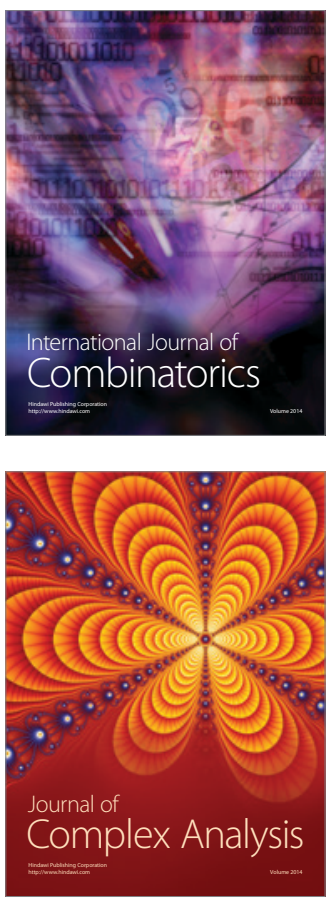

International Journal of

Mathematics and

Mathematical

Sciences
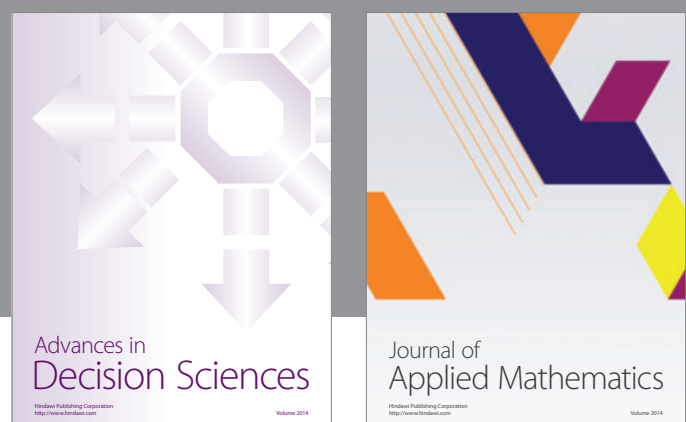

Journal of

Applied Mathematics
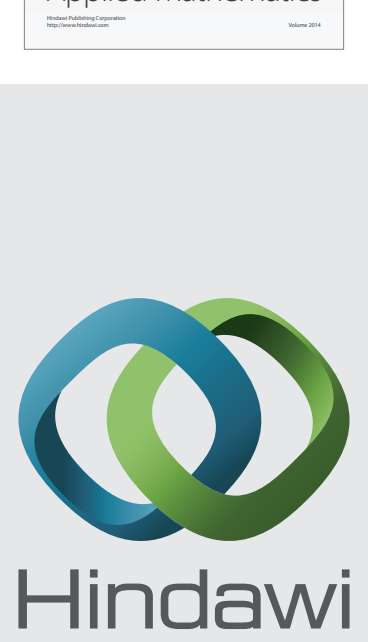

Submit your manuscripts at http://www.hindawi.com
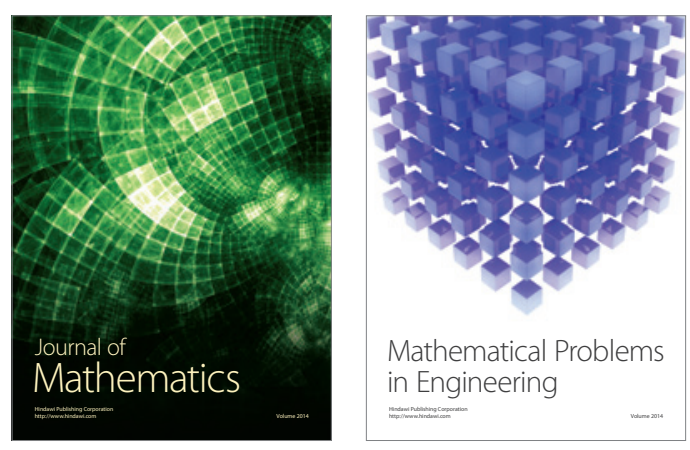

Mathematical Problems in Engineering
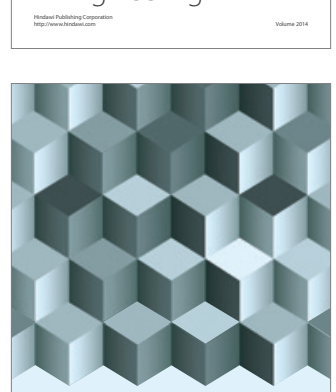

Journal of

Function Spaces
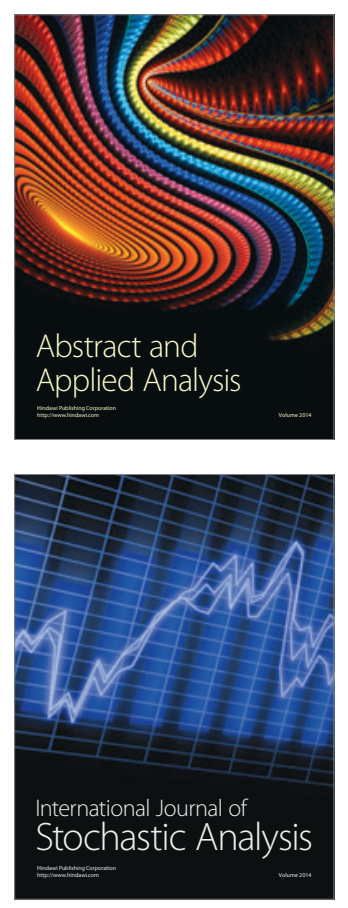

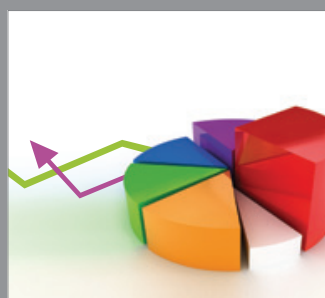

ournal of

Probability and Statistics

Promensencen
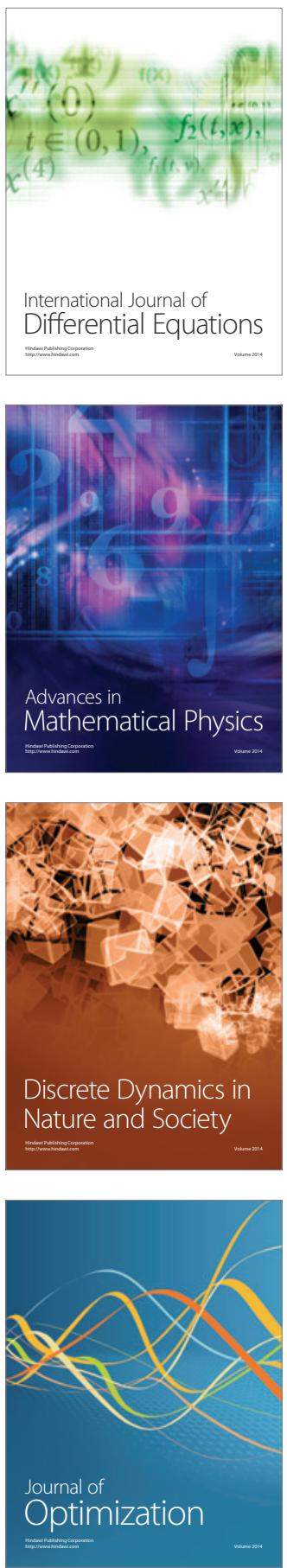